\title{
Pemodelan CAD 3D Tulang Femur dari data CT Scan
}

\author{
U.A. Salim ${ }^{1, *}$, F. Rizky ${ }^{1}$ \\ 1Departemen Teknik Mesin dan Industri Fakultas Teknik Universitas Gadjah Mada \\ Jalan Grafika No. 2 Yogyakarta 55261 \\ e-mail: *1urip-as@ugm.ac.id
}

\begin{abstract}
Abstrak
Rekontruksi tulang yang diawali dengan pembacaan tampilan 2D dari CT-Scan merupakan metode yang sudah lazim dilakukan oleh dokter bedah ortopedi. Tindakan ini merupakan bagian dari perencanaan sebelum operasi (preoperative planning). Salah satu tujuan tindakan ini adalah untuk menentukan jenis dan ukuran implan tulang tiruan. Pembacaan tampilan dari 2D dari CT-scan semata memungkinkan terjadi kesalahan intepretasi terhadap bentuk tulang karena ada bagian geometri tulang di belakang tampilan yang tidak jelas. Hanya dengan tampilan 2D saja, dokter bedah juga tidak bisa melakukan proses penyesuaian (fitting) implan template. Fitting implan template akan menjadi lebih mudah jika dilakukan menggunakan piranti lunak yang biasa digunakan untuk perancangan dengan CAD. Oleh karena itu pemodelan dari data CT-scan menjadi bentuk model solid 3D menjadi perlu dilakukan. Tulisan ini bisa memberikan prosedur yang dapat digunakan untuk memodelkan tulang dari data CT-scan sehingga menjadi bentuk model CAD 3D. Dengan model CAD 3D maka dokter bedah dapat melakukan proses fitting implan template dengan baik. Disisi lain, desainer dapat merancang implan tulang pasien secara personal.
\end{abstract}

Kata kunci: 2D CT-Scan, model tulang femur, CAD 3D.

\begin{abstract}
The bone reconstruction, which started by reading a 2D display from a CT scan, is a method commonly used by orthopedic surgeons. This action is part of preoperative planning. One purpose of this action is to determine the type and size of artificial bone implants. The reading of a $2 D$ view from a CT scan only can occur misinterpretation of the shape of the bone due to an unclear regions of the bone geometry behind the view. Only with a $2 D$ view, the surgeon also cannot adjust the implant template. The implant fitting template will be easier if done using software commonly used for CAD design. Therefore modeling 3D solid from of CT scan data is necessary. This paper can provide procedures that can be used to model bones from CT-scan data to develop a 3D CAD model. With the 3D CAD model, the surgeon can properly process the implant template. On the other hand, designers can design patient bone implants personally
\end{abstract}

Keywords: 2D CT-Scan, model tulang femur, CAD 3D.

\section{PENDAHULUAN}

Pembedahan dengan menggunakan tulang prosthetic yang banyak menarik peneliti adalah pembedahan hip Joint atau Hip Replacement. Hip replacement merupakan prosedur bedah yang memiliki tingkat keberhasilan yang cukup tinggi. Secara keseluruhan Hip replacement 
merupakan prosedur pembedahan dengan tujuan untuk mengganti upper end of femur yang rusak.

Prosedur bedah Hip Replacement yang ada pada saat ini adalah dengan menggunakan template tulang prosthetic sebagai acuan yang nanti akan digunakan sebagai prosthetic implant pada pasien. Dokter bedah akan menentukan tulang prosthetic berdasarkan CT Scan pasien, kemudian disaat pembedahan, dokter akan mengeluarkan femur pasien dan menentukan apakah template tulang prosthetic akan digunakan atau dimodifikasi terlebih dahulu.

Rekontruksi tulang yang dimulai dari pembacaan tampilan 2D CT-Scan merupakan metode yang sudah lazim dilakukan oleh dokter bedah ortopedi(Akkoul, Hafiane, Rozenbaum, Lespessailles, \& Jennane, 2017). Kegiatan ini merupakan bagian dari tindakan sebelum operasi (preoperative planning). Hal ini dilakukan untuk menentukan jenis dan ukuran implan tulang tiruan template (Kobayashi et al., 2012). Bahkan, template tulang prosthetic yang ada pada saat ini merupakan template orang-orang di kawasan Amerika, Eropa dan Asia. Oleh karena itu, pada beberapa pasien implan template ini menjadi tidak sesuai, dan dokter bedah melakukan beberapa modifikasi template tulang prosthetic agar dapat digunakan dengan baik.

Pembacaan tampilan dari 2D CT-Scan memungkinkan kesalahan intepretasi bentuk tulang karena ada bagian geometri tulang di belakang tampilan yang tidak jelas. Selanjutnya, hanya dengan tampilan 2D CT-Scan dokter bedah tidak bisa melakukan proses penyesuaian (fitting) implan template. Bahkan, teknologi image processing untuk rekonstruksi tulang telah berkembang dengan sangat pesat seperti pemodelan 3D dengan CT-Scan (Computed Tomography) dan MRI (Magnetic Resonance Imaging), akurasi model 3D tulang masih menyisakan persoalan (Lalone, Willing, Shannon, King, \& Johnson, 2015; Rathnayaka et al., 2012)

Fitting implan template akan menjadi lebih mudah jika dilakukan menggunakan piranti lunak yang biasa digunakan untuk perancangan dengan CAD seperti AutoCAD, SolidWork, CATIA dan yang lainnya. Oleh karena itu ada peneliti yang menggunakan AutoCAD untuk membuat sketsa implan pada tampilan 2D CT-Scan (Shapi'i, Sulaiman, Hasan, Prabuwono, \& Kassim, 2012). Evaluasi keteknikan seperti analisis kekuatan tulang menggunakan FEM pada model tulang dari CT-Scan juga masih menjadi kendala(Bonaretti, Seiler, Boichon, Reyes, \& Büchler, 2014; Couteau \& Payan, 2006; Rahim, Norouzi, Rehman, \& Saba, 2017).

Tulisan ini memberikan prosedur yang dapat digunakan untuk memodelkan tulang dari data CT-Scan sehingga menjadi bentuk model CAD 3D. Dengan model CAD 3D maka dokter bedah dapat melakukan pengukuran tulang pasien lebih akurat dan proses fitting implan template dengan baik. Disisi lain, desainer dapat menggunakan prosedur ini untuk merancang implan tulang pasien secara personal.

\section{METODE PENELITIAN}

Penelitian ini adalah pemodelan yang memanfaatkan piranti lunak gratis (opensource) bebas dan beberapa dengan lisensi gratis terbatas, sehingga mahasiswa atau industri kecil juga dapat melakukannnya.

Dalam penelitian ini, penulis menggunakan beberapa piranti lunak yaitu: a) 3D slicer untuk mengubah data CT-Scan tulang menjadi model tiga dimensi dalam bentuk format .stl, b) 3Ds Max untuk mengubah format .stl menjadi .sat, dan c) Autodesk Inventor untuk membuat model CAD 3D tulang dan merancang implan personal.

Urutan kegiatan penelitian ini meliputi: 
1. Persiapan, dilakukan untuk mengevaluasi kesalahan (error) data dari CT-Scan. Datadata yang tidak dikehendaki untuk membuat model dapat disisihkan. Eliminasi data dilakukan dengan piranti 3D Slicer.

2. Pemodelan 3D, dilakukan dengan piranti 3D-Slicer yang bekerja berdasarkan prinsip volum rendering dan disimpan dalam format .stl,

3. Penghalusan mesh, dilakukan untuk membuat geometri model mempunyai kelengkungan-kelengkungan yang baik. Tahapan ini dilakukan dengan piranti lunak Meshlab.

4. Konversi model, dari format .stl menjadi sat dilakukan dengan piranti 3Ds Max.

5. Pembacaan dan pemrosesan model 3D. Pada penelitian ini menggunakan piranti lunak Autodesk Inventor. Pada tahap ini dapat dialakukan pengukuran dimensidimensi dari model 3D tulang femur dan dapat dilakukan proses fitting model template implan dengan mudah.

\section{HASIL DAN PEMBAHASAN}

\section{Prosedur Pemodelan}

Berikut ini adalah langkah langkah yang dilakukan dalam pemodelan CAD 3D dengan beberapa piranti lunak dan pengukuran dimensi tulang proximal femur seorang pasien pada praoperasi yang dilakukan secara berurutan.

\section{A. Persiapan}

1. Menentukan dan memilih data-data dari CT-scan yang akan dijadikan model 3D Biasanya data yang digunakan dibawah folder DICOM.

2. Beberapa data dari CT-Scan mungkin terdapat images yang rusak, kerusakan ini dapat diperiksa. Jika jumlah image yang salah sedikit maka image tersebut dapat diabaikan (dihapus), namun jika jumlahnya terlalu banyak sebaiknya file ini tidak digunakan.

3. Menentukan parameter ortophometric tulang yang akan diukur. Objek penelitian ini adalah tulang femur dan parameter-parameter yang diukur pada penelitian ini (Park, Bae, Koo, \& Kim, 2014) yaitu:
a. Poros Femural isthmus
b. Sumbu anatomi femoralis
c. Femoral head dan sumbu x femur
d. Sudut poros leher femoral
e. Anterversion
f. Index Canal Flare

\section{B. Pembuatn Model 3 Dimensi}

1. Data CT Scan yang tidak ada error diproses menjadi model 3D dengan menggunakan 3D-Slicer. Pada tahapan ini, file DICOM yang terdapat pada data CT-scan dapat ditemukan dengan menekan tombol icon data.

2. Setelah data DICOM dari CT-scan dibuka, 3D Slicer akan menampilkan keseluruhan isi data-data CT-scan. Kemudian dipilih satu data yang mengandung semua komponen irisan. Dari data inilah model 3D dapat dibuat dengan mudah. Centang pada bagian unknwon, dimana file ini merupakan file yang berisi semua irisan yang digunakan untuk pemodelan 3D. 
3. Proses rendering dilakukan dengan memilih menu volume rendering, dimana data yang berisi irisan-irisan model akan dikonversi menjadi gumpalan titik-titik (point cloud) yang mengisi ruang model yang terbaca secara 3D.

4. Proses rendering meliputi keseluruhan data dari CT-Scan yang mencakup semua bagian tubuh yang di-scan. Oleh karena objek penelitian ini adalah proximal femur, maka dibuat kubus bidang pemotongan untuk menyisakan bagian proximal femur saja.

5. Tahap selanjutnya adalah memberi keterangan ruang model. Ini dilakukan dengan menekan tombol threshol deffect dan memberinya label. Pemilihan warna dapat dilakukan dengan mengarahkan pada bagian model 3D dan mengganti warnanya.

6. Dengan memilih tombol change island effect dapat dilakukan identifikasi bagian-bagian tulang. Dalam hal ini identifikasi dilakukan pada bagian femur dan acetabulum saja (Gambar 1).

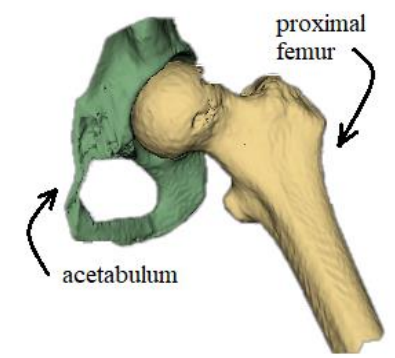

Gambar 1. Model 3D dari proximal femur dan acetabulum.

7. Tombol make model effect digunakan untuk memberikan label pada masing-masing komponen tulang. Sejak diberikan label yang berbeda maka model 3D dapat disimpan terpisah menurut labelnya.

\section{Penghalusan dan perbaikan Mesh}

Tahapan ini dilakukan untuk memperbaiki mesh model format .stl. Meshlab digunakan untuk menghilangkan point cloud yang tertindih satu sama lain. Apabila ada point cloud yang bertindih, maka besarnya data akan bertambah dan menyulitkan ketika membangun bentuk solid 3D. Meshlab juga memiliki fungsi untuk menyatukan bidang-bidang berdekatan sehingga data lebih sederhana.

Beberapa fitur Meslab yang biasanya digunakan untuk mempermudah pembangunan bentuk solid tiga dimensi adalah sebagai berikut;

1. Pada menu Cleaning and Repairing dapat digunakan beberapa fitur berikut:

a. Merge Close Vertices digunakan untuk mengurangi point cloud dan bidang pada mesh tiga dimensi.

b. Remove Duplicate Faces dapat digunakan agar terhindar dari point cloud yang bertindihan sehingga menyulitkan dalam membentuk solid tiga dimensi.

c. Remove Duplicate Vertices berfungsi untuk menghilangkan point cloud yang bertindih agar mengurangi jumlah faces yang ada.

d. Remove Zero Area Face berfungsi untuk menghilangkan secara otomatis point cloud yang terlalu jauh dari mesh dan point cloud yang tidak membentuk bidang.

2. Pada menu Smoothing,Pairing\&Deformation dapat dipilih fitur Depth Smooth untuk memperhalus bagian permukaan dari bentuk tiga dimensi. 


\section{Konversi format data}

Penghalusan model dengan Meshlab masih berupa format .stl yang didefenisikan sebagai point cloud yang berbentuk tiga dimensi. Konversi format data dari .stl menjadi .sat dilakukan dengan piranti Autodesk 3Ds-max. Konversi format data ini membutuhkan waktu lama yang tergantung pada kerumitan dan banyak point cloud yang akan di-generate.

\section{E. Pengukuran dimensi proximal femur}

File model dengan format .sat dapat dibuka dengan piranti Autodesk Inventor sehingga lebih mudah dalam menentukan dimensinya. Cara menetukan dimensi adalah sebagai berikut:

a. Menentukan arah pandangan gambar dan plane yang tepat sehingga memungkinkan data tercermin pada posisi yang benar (Gambar 2 (a)).

b. Memproyeksikan data melalui plane yang ada, kemudian membuat sketch pada garis proyeksi (Gambar 2 (b)).

c. Mengubah tampilan sehingga mempunyai batas yang jelas (Gambar 2(c).

Membuat sketsa geometri sederhana dan mengidentifikasi titik-titik pengukaran sehingga dapat ditentukan dimensi-dimensi pada posisi terkait (Gambar 2(d)).

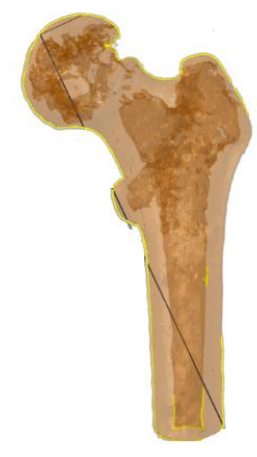

(a)

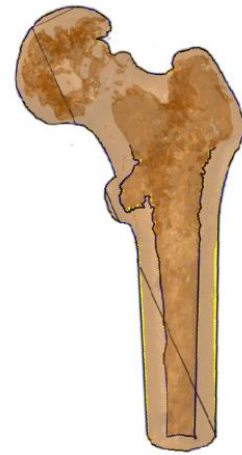

(b)

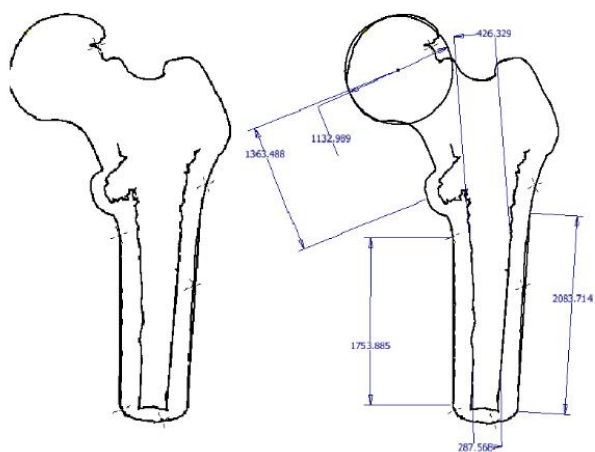

(c)

(d)

Gambar 2. Urutan proses penentuan geometri proximal femur.

\section{Pembahasan}

Prosedur yang dibuat ini memang cukup panjang dan bahkan menghabiskan banyak waktu, namun demikian cukup efektif untuk dilakukan dengan berbagai keterbatasan. Pemodelan 3D didasarkan pada data CT-Scan pasien sampai saat ini masih mejadi topik yang hangat untuk dibahas. Terlalu banyaknya point yang di-generate menjadikan kesulitan tersendiri dalam penentuan batas-batas wilayah geometrinya. Namun demikian, secara umum pemodelan 3D yang didasarkan pada protokol CT-Scan masih memberikan akurasi yang lebih baik dari pada 2D (Lalone et al., 2015).

Banyaknya point-cloud yang di-generate oleh CT-Scan menjadi permasalahan sendiri ketika digabungkan dengan perangkat lunak untuk keperluan perancangan (CAD) dan evaluasi kekuatan (dengan FEM). Sehingga Couteau, et al, (2000) harus melakukan modifikasi model untuk keperluan evaluasi dengan FEM menggunakan algoritma mesh-matching.

Penelitian ini berbeda dengan yang telah dilakukan oleh Salim, et al, (2009) dalam hal generating point-cloud yang digunakan. Pada penelitian yang lalu point-cloud di-generate dengan surface scan sehingga model 3D dibuat dengan bantuan membuat NURBS, sedangkan penelitian ini menggunakan data yang di-generate oleh CT-Scan. 


\section{KESIMPULAN}

Prosedur pemodelan 3D dengan CAD ini telah mengkombinasikan image processing dari geometri proximal femur dengan piranati CAD yang biasa digunakan untuk perancangan. Dengan prosedur ini tidak hanya dapat dilakukan proses fitting model implan templete dengan model geometri tulang 3D, tetapi juga dapat digunakan untuk merancang bentuk bentuk implan tulang secara personal.

\section{DAFTAR PUSTAKA}

Akkoul, S., Hafiane, A., Rozenbaum, O., Lespessailles, E., \& Jennane, R. (2017). 3D Reconstruction of the proximal femur shape from few pairs of $\mathrm{x}$-ray radiographs. Signal Processing: Image Communication, 59(February 2016), 65-72. https://doi.org/10.1016/j.image.2017.03.014

Bonaretti, S., Seiler, C., Boichon, C., Reyes, M., \& Büchler, P. (2014). Image-based vs. meshbased statistical appearance models of the human femur: Implications for finite element simulations. Medical Engineering and Physics, 36(12), 1626-1635. https://doi.org/10.1016/j.medengphy.2014.09.006

Couteau, B., \& Payan, Y. (2006). The mesh-matching algorithm: an automatic 3D mesh generator for finite element structures. Arxiv Preprint Physics/0606232, 33(8), 1005-1009. https://doi.org/10.1016/S0021-9290(00)00055-5

Kobayashi, A., Ishii, Y., Takeda, M., Noguchi, H., Higuchi, H., \& Toyabe, S. (2012). Comparison of analog 2D and digital 3D preoperative templating for predicting implant size in total knee arthroplasty. Computer Aided Surgery, 17(2), 96-101. https://doi.org/10.3109/10929088.2011.651488

Lalone, E. A., Willing, R. T., Shannon, H. L., King, G. J. W., \& Johnson, J. A. (2015). Accuracy assessment of 3D bone reconstructions using CT: An intro comparison. Medical Engineering and Physics, 37(8), 729-738. https://doi.org/10.1016/j.medengphy.2015.04.010

Park, B. K., Bae, J. H., Koo, B. Y., \& Kim, J. J. (2014). Function-based morphing methodology for parameterizing patient-specific models of human proximal femurs. CAD Computer Aided Design, 51, 31-38. https://doi.org/10.1016/j.cad.2014.02.003

Rahim, M. S. M., Norouzi, A., Rehman, A., \& Saba, T. (2017). 3D bones segmentation based on CT images visualization. Biomedical Research (India), 28(8), 3641-3644.

Rathnayaka, K., Momot, K. I., Noser, H., Volp, A., Schuetz, M. A., Sahama, T., \& Schmutz, B. (2012). Quantification of the accuracy of MRI generated 3D models of long bones compared to CT generated 3D models. Medical Engineering and Physics, 34(3), 357-363. https://doi.org/10.1016/j.medengphy.2011.07.027

Shapi'i, A., Sulaiman, R., Hasan, M. K., Prabuwono, A. S., \& Kassim, A. Y. M. (2012). Digital two dimensional (2D) implant design for pre-operative planning in Total hip Arthroplasty. International Journal on Electrical Engineering and Informatics, 4(1), 67-77. https://doi.org/10.15676/ijeei.2012.4.1.6 